\title{
The Clinical Medication Safety Based on Petri Net Monitoring
}

\author{
Zhi-Hui Huang \\ Fujian University of Traditional Chinese Medicine, 1 Qiuyang Road, Minhou Shangjie, \\ Fuzhou, Fujian, China, 350122
}

Keywords: Clinical pathway, Task reliability, Fault tree, Human reliability, Petri net.

\begin{abstract}
Pharmacovigilance and rational use of drugs, clinical application and evaluation, drug risk management is an important content of drug epidemiology. How to take advantage of Petri net monitoring Clinical Medication Safety in the hospital information system, obtain human reliability fault data, and using Petri model analysis identification of Pharmacovigilance and rational use of drugs, establishment rational use of medicines (RUM). Based on fault tree analysis (FTA) focus on analyze the medical staff human reliability about hospital clinical pathway system safety monitoring and rational drug use. Methods: Application OpenFTA software, the research based on Petri net fault tree analysis, fault tree for qualitative and quantitative analysis, drug safety management of the fault tree is obtained by Monte Carlo simulation of minimum cut sets. Results: Through the simulation calculation the probability of top event-drug safety incidents occur. Conclusion: Based on Petri net monitoring Clinical Medication Safety of fault tree method may help the qualitative and quantitative analysis the influence factors of adverse events, for the development of safety precautions, improving medication safety.
\end{abstract}

\section{Introduction}

Clinical pathway system is the use of information technology, the basis of evidence-based medicine and the purpose of prospective therapeutic effect and medical quality control, hoping to achieve strict and standard working process. Researches for monitoring the clinical safety and reasonable dosage are engaged by scholars, such as use clinical pathway and the digital management of hospital medicine quality to advance reasonable dosage [1], adopt the hospital management system to reasonable medicine dosage and monitor medicine [2], take efficient interfering actions to promote medical dosage, and so on. Reliability methods have been widely used in risk analysis of medical surgeries. Combine a fault tree with Markov models studied with data collected from a general hospital, to illustrate the operational process of the proposed method [3]. From the risk factors of drugs, risks that can easily arise in all aspects of clinical drug use were described and analyzed [4]. Agile Clinical Pathway System may help hospital strength the research on the adverse events influence factors, and implementation self-evaluation for traditional Chinese medicine (TCM) reasonable dosage management, improvement medication safety.

\section{Use FTA Evaluation Tcm Prescription Management Task Reliability}

\section{The Meaning of FTA}

The Fault Tree Analysis is a well-known method to analysis the safety and reliability of complex systems. It contains qualitative analysis and quantitative analysis. Qualitative analysis researches the causality of FTA construes and incidents causality, while 
quantitative analysis studies the probability of all reasons and uses FTA to calculate the probability of top events. We can use the Fault Tree to do qualitative analysis and quantitative analysis the minimum cut sets and the minimum path sets, then make sure the probability of all reasons, so that the hospitals can master the abilities and results of every segment of Chinese medicine prescription includes physicians and nurses to finish the tasks.

\section{The Reliability of Chinese Prescription Management Task}

The task reliability of Chinese prescription management means the ability of the system to finish the task in a certain condition and time. It indicates that Chinese prescription management based on the request of clinical applied safe management reduces the clinical medication errors and tries to avoid the adverse events. Petri net which can describe clearly the common phenomenon such as Synchronization, concurrency, distribution, conflict, resource sharing and so on, is a system model showed by web and an efficient way of doing discrete event dynamic system modeling, analysis and design. When we make the minimum cut sets, it has a large calculated amount problem. This can be solved by graph theory [5-7]. In the research of system software function and task reliability, methods such as the SMITH submits that through the evaluation for the different parts of system function it can make reliability evaluation by the system function. SMITH supports that the failure mode of components of system function (including function and additive attribute) can be recognized in the progress of executing the task (function) [8]. Black box testing method and system testing method support that the purpose of using artificial or automatic methods to operate or test the layout about a function (task) is to test whether it satisfies the prescribed demands.

\section{The Monitor of Prescription Management Task Reliability Failure}

Agile Clinical Pathway System can be used to analyze the medicine dosage errors and Adverse Drug Reactions (ADR) to promote reasonable medicine dosage. The retrospective analysis can be adapted to census and analysis the statistics collected from the ages of patients, medicine varieties, route of administration involved organs or system and clinical manifestation, etc. For example, physician version clinical pathway table is used to make sure the process in the clinical pathway diagnosis consisting in the diagnosis work key medical advice (long-term medical advice and temporary medical advice), nursing service, variability records, and chronological order. It is unavoidable that different patients may have variation and different reactions for medicine dosage, so the physicians can do pertinent analysis and integration by the analysis of the reason for variation and the safety in prescription management. This can stipulate the behavior of medical staff's reasonable diagnosis, the practice of medicine and service sense, also improvement management level and system efficiency in the hospital, and then promotion the whole hospital's medical treatment quality and working efficiency.

A hospital medication failure incident was surveyed clinical pathway system function and human reliability shown in Table 1.

\section{Reliability Solution by Fault Tree Minimum Cut Sets Based on Petri Net Model for Drug Safety Task}

For less than method of failure analysis in these cases, in order to make failure analysis efficient, accurate, we apply Petri net to do modeling analysis of these failure events in this paper. At a given initial state using Petri nets' reachability (refers to the termination of a given initial marking and identification Petri nets) can determine whether the 
system may run into a specified state, using Petri nets' activity definition can analysis the system besides get the information about corresponding processes and events likely to occur under specified conditions and frequency of occurrence. Can assume: E1: doctor of TCM with the wrong medicine, E2: pharmacists work error, E3: nurse dosing errors, E4: physicians prescription errors, E5: pharmacists mix discrepancies, E6: injection, E7 leakage: pharmacists wrong operation to match the wrong medicine, E8: system measures implementation does not reach the designated position, E9: dispensing process specification.E10 system data is not handled in time, E11 drug errors. By using the basic elements of Petri nets connecting said logic fault tree model shown in Fig. 1. A safety management system of minimum cut sets shown in Table 2.

Table 1. Table headings

\begin{tabular}{|c|c|c|c|}
\hline $\begin{array}{l}\text { Failure events and the } \\
\text { corresponding number }\end{array}$ & FP & $\begin{array}{l}\text { Failure events and the corresponding } \\
\text { number }\end{array}$ & $\mathrm{FP}$ \\
\hline $\begin{array}{l}\text { TCM omission of the number of } \\
\text { drugs X1 }\end{array}$ & רת & $\begin{array}{l}\text { No for Adverse Drug Reaction } \\
\text { Monitoring X17 }\end{array}$ & 0.02 \\
\hline $\begin{array}{l}\text { No dose adjustment for special } \\
\text { patients } X 2\end{array}$ & 0.03 & $\begin{array}{l}\text { No rational use of drugs with } \\
\text { Physicians X18 }\end{array}$ & 0.06 \\
\hline $\begin{array}{l}\text { Incorrect judgment of } \mathrm{TCM} \\
\text { prescriptions rationality } \mathrm{X} 3\end{array}$ & 0. & Error handling medical advice X19 & 0.06 \\
\hline $\begin{array}{l}\text { Workload of pharmacists uneven } \\
\text { load X4 }\end{array}$ & 0. & Dispensing are not standardized X20 & 0.06 \\
\hline Faulty dispensing of TCM X5 & 0.01 & Ignore incompatibility of drugs X21 & 0.05 \\
\hline Give wrong injection $\mathrm{X} 6$ & $0 .($ & $\begin{array}{l}\text { Drug placed disorder, similar } \\
\text { packaging without distinction X22 }\end{array}$ & 0.06 \\
\hline $\begin{array}{l}\text { Forgetting to dispensing the } \\
\text { medicine } X 7\end{array}$ & 0.0 & $\begin{array}{l}\text { Failure to pick up medicine in order } \\
\text { by prescription } X 23\end{array}$ & 0.06 \\
\hline Clerical error $\mathrm{X} 8$ & & $\begin{array}{l}\text { No timely communication with the } \\
\text { crabbed handwriting prescribing } \\
\text { physician X24 }\end{array}$ & 0.06 \\
\hline $\begin{array}{l}\text { Unfamiliar with drugs lead to } \\
\text { repeated drugs use X9 }\end{array}$ & 0 & New drug suppliers mistake X25 & 0.04 \\
\hline $\begin{array}{l}\text { Unfamiliar with the use of } \\
\text { pharmaceutical dosage forms lead } \\
\text { to errors X10 }\end{array}$ & $0 .($ & $\begin{array}{l}\text { Different batch number is not set for } \\
\text { the same drugs(The period of validity } \\
\text { is consistent) X } 26\end{array}$ & 0.01 \\
\hline $\begin{array}{l}\text { Physicians do not understand } \\
\text { drug policy (Medicare patients' } \\
\text { drugs use )X11 }\end{array}$ & 0.0 & $\begin{array}{l}\text { The same drug different vendors, not } \\
\text { in accordance with the first-in, } \\
\text { first-out X27 }\end{array}$ & 0.02 \\
\hline Dispensing expired drugs X12 & 0.04 & $\begin{array}{l}\text { System failed to predict the drug } \\
\text { dosage X } 28\end{array}$ & 0.02 \\
\hline $\begin{array}{l}\text { No clearly account to patients } \\
\text { when they check X13 }\end{array}$ & 0.0 & $\begin{array}{l}\text { Cheap drug vendor specifications } \\
\text { frequently changed lead to error X } 29\end{array}$ & 0.01 \\
\hline $\begin{array}{l}\text { Drug name error (with different } \\
\text { drugs of the same name or drug } \\
\text { synonym) X14 }\end{array}$ & 0.03 & $\begin{array}{l}\text { Part of the emergency medicine when } \\
\text { close to the period of validity not } \\
\text { invalid processing X } 30\end{array}$ & 0.03 \\
\hline Shifting of duty unclear X15 & 0.03 & $\begin{array}{l}\text { part of the drug in short supply or } \\
\text { itself Valid for a short,unable to meet } \\
\text { the specified requirements } X 31\end{array}$ & 0.01 \\
\hline $\begin{array}{l}\text { Prescription review ineffective } \\
\text { X16 }\end{array}$ & 0.02 & $\begin{array}{l}\text { Drug name use common name, easy to } \\
\text { chaos X32 }\end{array}$ & 0.03 \\
\hline
\end{tabular}

Note: Fail Probability FP.

Applying OpenFTA software to Fault Tree for qualitative and quantitative analysis, doing Monte Carlo simulation and getting prescription medicine management system fault tree minimal cut sets. Through 10000 times simulation calculations finally found that the probability of Unfamiliar with drugs lead to repeated use TCM omission of the 
number of drugs. No dose adjustment for special patients is more than the probability of Clerical error, TCM omission of the number of drugs. The maximum probability of top event is Allot expired drugs, incorrect judgment of TCM prescriptions rationality, Workload of pharmacist's uneven load Workload of pharmacist's uneven load which is $1.854 \times 10^{-4}$ by simulation calculations. Based on the above analysis, we can prioritize critical failure modes for effective control, thus minimizing the top event (medication error event) occur.

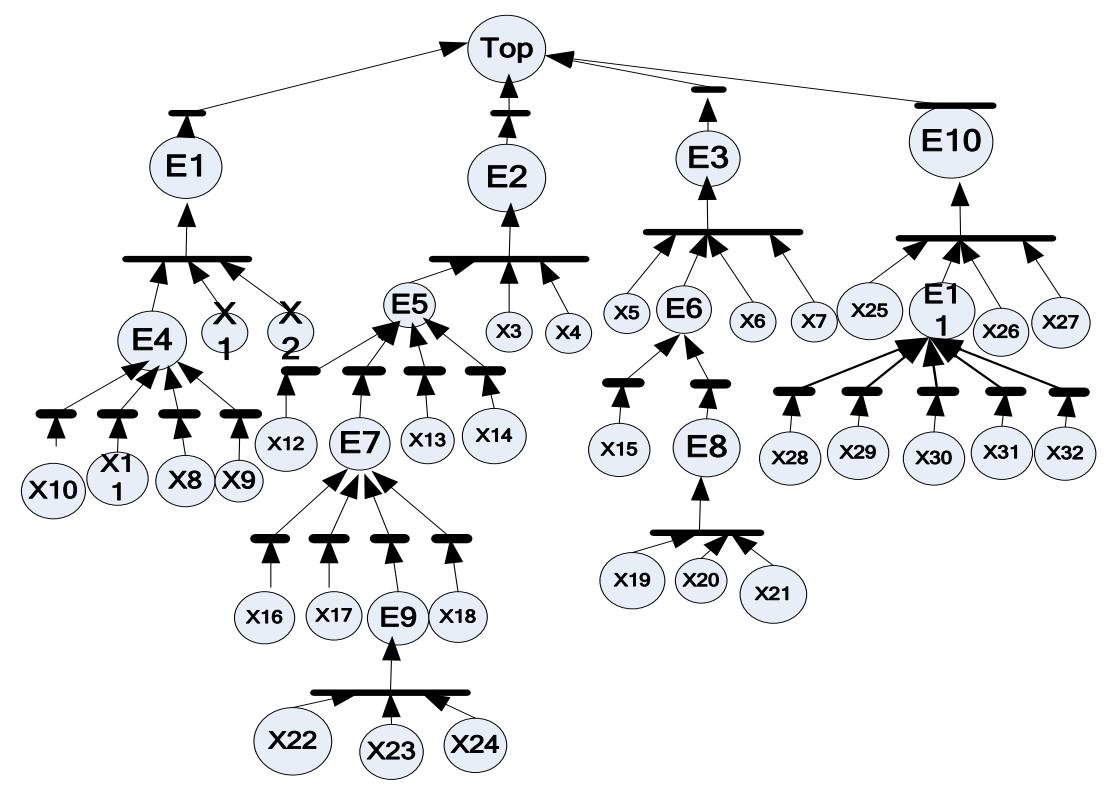

Figure 1. Petri net model diagram of a TCM prescription management system

\section{Discussion}

In this instance through the establishment of Petri net model, using relational matrix analysis to obtain a minimum cut sets. The designed fault tree have Clear causal relationship, image, and minimum cut sets based on Petri nets solve fast and can be reassuring. But the application of Petri net model for failure analysis in quantitative analysis there are still insufficient: (1) The system failure event is more complicated than Reliability of prescription medicine management tasks, the supporting data need to establish specific fault information database and than the operation and maintenance of database support. (2) When quantitative analysis, with the method of statistical analysis of historical data and expert survey conducted analysis, come to the probability of bottom event occurrence of the past and thus predict the probability of occurrence now or in the future, with some limitations. Monte Carlo simulation algorithm can determine the probability of occurrence of the top event statistics, the number of failures, can also determine the cut-set statistics, but the simulation does not guarantee that all of the cut sets come. 
Table 2. The management system of Chinese medical description of minimum cut sets

\begin{tabular}{|c|c|c|}
\hline Minimal cut sets & Failure mode meaning minimal cut sets Physical Description & Probability \\
\hline$\{\mathrm{X} 12, \mathrm{X} 1, \mathrm{X} 2\}$ & $\begin{array}{l}\text { Dispensing expired drugs, TCM omission of the number of } \\
\text { drugs, No dose adjustment for special patients }\end{array}$ & $2.4 \times 10^{-5}$ \\
\hline$\{\mathrm{X} 13, \mathrm{X} 1, \mathrm{X} 2\}$ & $\begin{array}{l}\text { No clearly account to patients when they check, TCM omission } \\
\text { of the number of drugs, No dose adjustment for special patients }\end{array}$ & $6.0 \times 10^{-5}$ \\
\hline$\{\mathrm{X} 10, \mathrm{X} 1, \mathrm{X} 2\}$ & $\begin{array}{l}\text { Unfamiliar with the use of pharmaceutical dosage forms lead to } \\
\text { errors, TCM omission of the number of drugs, No dose } \\
\text { adjustment for special patients }\end{array}$ & $3.0 \times 10^{-5}$ \\
\hline$\{\mathrm{X} 11, \mathrm{X} 1, \mathrm{X} 2\}$ & $\begin{array}{l}\text { Physicians do not understand the drug policy (Medicare patients' } \\
\text { drugs use ),TCM omission of the number of drugs, No dose } \\
\text { adjustment for special patients }\end{array}$ & $1.8 \times 10^{-5}$ \\
\hline$\{\mathrm{X} 16, \mathrm{X} 3, \mathrm{X} 4\}$ & $\begin{array}{l}\text { Prescription review ineffective, Incorrect judgment of TCM } \\
\text { prescriptions rationality, Workload of pharmacists uneven load }\end{array}$ & $3.2 \times 10^{-5}$ \\
\hline$\{\mathrm{X} 17, \mathrm{X} 3, \mathrm{X} 4\}$ & $\begin{array}{l}\text { No for Adverse Drug Reaction Monitoring, Incorrect judgment } \\
\text { of TCM prescriptions rationality, Workload of pharmacists } \\
\text { uneven load }\end{array}$ & $3.2 \times 10^{-5}$ \\
\hline$\{\mathrm{X} 18, \mathrm{X} 3, \mathrm{X} 4\}$ & $\begin{array}{l}\text { No rational use of drugs with Physicians, Incorrect judgment of } \\
\text { TCM prescriptions rationality, Workload of pharmacists uneven } \\
\text { load }\end{array}$ & $9.6 \times 10^{-5}$ \\
\hline$\{\mathrm{X} 12, \mathrm{X} 3, \mathrm{X} 4\}$ & $\begin{array}{l}\text { Dispensing expired drugs, Incorrect judgment of TCM } \\
\text { prescriptions rationality, Workload of pharmacists uneven load } \\
\text { Workload of pharmacists uneven load }\end{array}$ & $6.4 \times 10^{-5}$ \\
\hline$\{\mathrm{X} 13, \mathrm{X} 3, \mathrm{X} 4\}$ & $\begin{array}{l}\text { No clearly account to patients when they check, Incorrect } \\
\text { judgment of TCM prescriptions rationality, Workload of } \\
\text { pharmacists uneven load }\end{array}$ & $1.6 \times 10^{-5}$ \\
\hline$\{\mathrm{X} 14, \mathrm{X} 3, \mathrm{X} 4\}$ & $\begin{array}{l}\text { Drug name error (with different drugs of the same name or drug } \\
\text { synonym), Incorrect judgment of TCM prescriptions rationality, } \\
\text { Workload of pharmacists uneven load }\end{array}$ & $4.8 \times 10^{-5}$ \\
\hline $\begin{array}{l}\{X 5, X 6, X 15 \\
X 7\}\end{array}$ & $\begin{array}{l}\text { Faulty dispensing of TCM,Give wrong injection,Shifting of duty } \\
\text { unclear,Forgetting to dispensing the medicine }\end{array}$ & $4.8 \times 10^{-7}$ \\
\hline $\begin{array}{l}\{\mathrm{X} 25, \mathrm{X} 26 \\
\mathrm{X} 27, \mathrm{X} 28\}\end{array}$ & $\begin{array}{l}\text { New drug suppliers mistake, Different batch number is not set for } \\
\text { the same drugs (The period of validity is consistent), The same } \\
\text { drug different vendors, not in accordance with the first-in, } \\
\text { first-out, System failed to predict the drug dosage }\end{array}$ & $1.6 \times 10^{-7}$ \\
\hline $\begin{array}{l}\{\mathrm{X} 25, \mathrm{X} 26 \\
\mathrm{X} 27, \mathrm{X} 29\}\end{array}$ & $\begin{array}{l}\text { New drug suppliers mistake, Different batch number is not set for } \\
\text { the same drugs(The period of validity is consistent), The same } \\
\text { drug different vendors, not in accordance with the first-in, } \\
\text { first-out, Cheap drug vendor specifications frequently changed } \\
\text { lead to error }\end{array}$ & $8.0 \times 10^{-7}$ \\
\hline $\begin{array}{l}\{\mathrm{X} 25, \mathrm{X} 26 \\
\mathrm{X} 27, \mathrm{X} 30\}\end{array}$ & $\begin{array}{l}\text { New drug suppliers mistake, Different batch number is not set for } \\
\text { the same drugs(The period of validity is consistent), The same } \\
\text { drug different vendors, not in accordance with the first-in, } \\
\text { first-out, Part of the emergency medicine when close to the } \\
\text { period of validity not invalid processing }\end{array}$ & $2.4 \times 10^{-7}$ \\
\hline $\begin{array}{l}\{\mathrm{X} 25, \mathrm{X} 26 \\
\mathrm{X} 27, \mathrm{X} 31\}\end{array}$ & $\begin{array}{l}\text { New drug suppliers mistake, Different batch number is not set for } \\
\text { the same drugs(The period of validity is consistent), The same } \\
\text { drug different vendors, not in accordance with the first-in, } \\
\text { first-out, part of the drug in short supply or itself Valid for a } \\
\text { short, unable to meet the specified requirements }\end{array}$ & $2.4 \times 10^{-7}$ \\
\hline $\begin{array}{l}\{X 25, X 26 \\
X 27, X 32\}\end{array}$ & $\begin{array}{l}\text { New drug suppliers mistake, Different batch number is not set for } \\
\text { the same drugs(The period of validity is consistent), The same } \\
\text { drug different vendors, not in accordance with the first-in, } \\
\text { first-out, Drug name use common name, easy to chaos }\end{array}$ & $2.4 \times 10^{-8}$ \\
\hline
\end{tabular}




\section{Conclusions}

Application Open FTA software for Monte Carlo simulation analysis can get minimal cut sets for each occurrence probability, the probability of occurrence of the top event and the probability values of the reliability of each the bottom event for the top event occurred. Examples of the calculation results accord with the actual situation. The study has some reference value in such aspects as engineering practice and hospital clinical pathway drug safety management has a certain reference value. Clinical drug safety evaluation of the fault tree model, the development of this kind of model application field, fault diagnosis and algorithm implementation functions. We conclude that the Petri net monitoring studies provide a bridge between areas like rational use of drugs, pharmacovigilance and evidence based medicine.

\section{Acknowledgement}

This work was financially supported by Fujian province science and technology key projects (No: 2014H0021), Fund of Fujian Provincial Administration of Food and Drugs project (No.wzrk201304).

\section{References}

[1] Yao Linqing, Feng Xiaoli, Zhang Xin, Rui Xiaotong and Jin Yongxin. "Current Situation and Development Trend of the Digital Management of Hospital Drug Quality", Chinese Pharmaceutical Affairs, 2012, vol.26, no. 9, pp. 1027-1031.

[2] Chun-Jie Zhang, Chen Wenzhong. "In order to strengthen the management of outpatient pharmacy and doctor workstation information system realize the combination of drug inventory". Medical information, vol. 25, no. 1, pp. 81-81(2012).

[3] Frank Röhricht, Seema Gadhia, Rinku Alam, Melissa Willis, "Clinical Study: Auditing Clinical Outcomes after Introducing Off-Licence Prescribing of Atypical Antipsychotic Melperone for Patients with Treatment Refractory Schizophreni”, The Scientific World Journal, 2012: 512047.

[4] WU CHUANG, LU WEI, Risk Factors and Measures of Clical Medicine, china J Mod Drug Appl, 2012, 6(9): 126-129.

[5] Codetta-Raiteri D. "The conversion of dynamic fault trees to stochastic Petri nets, as a case of graph transformation". Electronic Notes in Theoretical Computer science, vol. 127, no. 2, pp. 45-60 (2005).

[6] Ding Caihong. "The application of Petri Net in the area of fault diagnosis", Computer Engineering And Design, vol. 21, pp, 22-24, (2000).

[7] Liu Zixian, Ni Xin, Liu Yiliu, Song Qinglu, Wang Yukun. "Gastric esophageal surgery risk analysis with a fault tree and Markov integrated model", Reliability Engineering \& System Safety, vol. 96, no. 12, pp. 1591-1600, (2012).

[8] Smith C, Sova D. "An Architectural Model for Software Reliability Quantification", Sources of Data.Reliability Engineering and System Safety, vol.64, pp. 279-290, (1999). 